SERRAGLIO, Priscila Zilli; ZAMBAM, Neuro José. Hermenêutica e constitucionalismo contemporâneo. Revista Eletrônica Direito e Política, Programa de Pós-Graduação Stricto Sensu em Ciência Jurídica da UNIVALI, Itajaí, v.10, n.2, $1^{0}$ quadrimestre de 2015. Disponível em: www.univali.br/direitoepolitica - ISSN 1980-7791.

\title{
HERMENÊUTICA E CONSTITUCIONALISMO CONTEMPORÂNEO
}

\author{
HERMENEUTICS AND CONTEMPORARY CONSTITUTIONALISM
}

\author{
Priscila Zilli Serraglio ${ }^{1}$ \\ Neuro José Zambam²
}

SUMÁRIO: Introdução; 1 . Em defesa da constituição e do estado democrático de direito - do porquê combater o protagonismo exacerbado da jurisdição no constitucionalismo contemporâneo; 2. A hermenêutica como possibilidade para a coerência e a integridade do direito - por uma teoria da decisão limitadora da discricionariedade interpretativa; Considerações finais; Referências das fontes citadas.

RESUMO: O presente estudo busca definir o papel da hermenêutica no constitucionalismo contemporâneo, combatendo a discricionariedade judicial. Inicia tratando brevemente da história constitucional e sobre como o paradigma da legalidade foi insuficiente para abarcar a complexidade do fenômeno jurídico no pós-segunda guerra, motivo que implica na ênfase da atuação jurisdicional e, via reflexa, traz à tona o dilema da discricionariedade interpretativa, atentando para a necessidade de se pensar uma teoria da decisão que limite o ato de julgar, sob pena de um esvaziamento normativo da Constituição, e de um aniquilamento da democracia e suas conquistas. Por fim, estabelece a evolução histórica da hermenêutica para demonstrar que esta e o Direito devem partilhar uma relação de complementaridade, a fim de refutar a subjetividade assujeitadora do intérprete solipsista e limitar a decisão judicial à

\footnotetext{
${ }^{1}$ Advogada. Mestranda do PPGD da Faculdade Meridional - IMED, Passo Fundo-RS, Brasil. Bolsista PROSUP-CAPES. Integrante dos grupos de pesquisa: 1) Multiculturalismo, minorias, espaço público e sustentabilidade; 2) Multiculturalismo e pluralismo jurídico. E-mail: pris_zs@hotmail.com. Lattes: <http://lattes.cnpq.br/5732131166139352>

2 Pós-doutorando em Filosofia na Universidade do Rio dos Sinos - Unisinos; Doutor em Filosofia pela PUCRS. Professor do Programa de Pós-graduação em Direito da Faculdade Meridional - IMED Mestrado. Professor do Curso de Direito (graduação e especialização) em Direito da Faculdade Meridional - IMED de Passo Fundo-RS, Brasil. Membro do Grupo de Trabalho, Ética e cidadania da ANPOF (Associação Nacional dos Programas de Doutor em Filosofia) pela PUCRS. Pesquisador da Faculdade Meridional. Coordenador do Grupo de Pesquisa: Multiculturalismo, minorias, espaço público e sustentabilidade. E-mail: neurojose@hotmail.com; nzambam@imed.edu.br.
} 
SERRAGLIO, Priscila Zilli; ZAMBAM, Neuro José. Hermenêutica e constitucionalismo contemporâneo. Revista Eletrônica Direito e Política, Programa de Pós-Graduação Stricto Sensu em Ciência Jurídica da UNIVALI, Itajaí, v.10, n.2, $1^{0}$ quadrimestre de 2015. Disponível em: www.univali.br/direitoepolitica - ISSN 1980-7791.

compreensão/interpretação adequada à Constituição, na qual os princípios desempenham papel fundamental de fechamento interpretativo do ordenamento.

Palavras-chave: Constitucionalismo; Discricionariedade; Ativismo judicial; Hermenêutica.

ABSTRACT: This study aims to define the hermeutic's role on the contemporary constitutionalism, therefore fighting the jurisdictional discretion. It begins addressing briefly the constitutional history and how the paradigm of legality was insufficient to cover the complexity of the legal phenomenon in the post-secondwar, reason that leads to the emphasis of the jurisdictional action and, consequently, implies the dilemma of interpretative discretion, reveling the need to thinking a theory of decision that limits the act of judging, risking, if not, a normative emptying of the Constitution, and the annihilation of democracy and its achievements. Finally, it establishes the historical development of hermeneutics to demonstrate that the Law and it should share a complementary relationship in order to combat the subjugating subjectivity of solipsistic interpreter and limit the jurisdictional decision to a proper comprehension/interpretation of the Constitution, in which the principles play a fundamental role of interpretive closure of the system.

Keywords: Constitutionalism; Discretion; Judicial activism; Hermeneutic.

\section{INTRODUÇÃO}

Ante o período histórico atual, pode-se afirmar que se vive, hoje, uma transição paradigmática marcada pela crise da modernidade, iniciada pelo esfacelamento das crenças e verdades burguesas, capitalistas e liberais, principalmente quando do pós-guerra, em 1945. Essa crise afeta todas as dimensões do humano, nelas incluída o Direito.

Por ser também cultural, todo o núcleo das questões jurídicas também é afetado e sofre modificações em razão do cerne de questões culturais. Nesse sentido, o Direito pressupõe certa estabilização dos valores caros para a comunidade política que com ele interage. O Direito se traduz historicamente pela busca do equilíbrio entre liberdade e poder, e, por isso, necessita de consensos para que a norma produza efeitos. 
SERRAGLIO, Priscila Zilli; ZAMBAM, Neuro José. Hermenêutica e constitucionalismo contemporâneo. Revista Eletrônica Direito e Política, Programa de Pós-Graduação Stricto Sensu em Ciência Jurídica da UNIVALI, Itajaí, v.10, n.2, $1^{0}$ quadrimestre de 2015. Disponível em: www.univali.br/direitoepolitica - ISSN 1980-7791.

Um dos principais campos do direito que tem sido afetado pelas mudanças do pós-guerra é aquele do constitucionalismo. Muito se tem escrito e debatido a respeito do Estado Constitucional de Direito e das evoluções e transformações que tem marcado essa área tão determinante para a ciência jurídica. Atualmente, o constitucionalismo passa por um novo momento, caracterizado pela revogabilidade da norma legal ante os enunciados constitucionais que consagram direitos fundamentais expressos e implícitos e vinculam os poderes ao seu estrito cumprimento.

Essa nova fase, justamente porque distinta das fases anteriores - liberal e social - tem sido cunhada como "neoconstitucionalismo" - movimento voltado ao estudo dos novos fenômenos constitucionais e suas consequências - e tem conquistado cada vez mais adeptos dentre os juristas, nacionais e internacionais.

Apesar de despontar grandes e inúmeras controvérsias, desde a sua terminologia quanto ao seu conteúdo, certo é que o fenômeno de um novo constitucionalismo impera, assim como, dentre as inúmeras discordâncias, há consenso de que houve ênfase no papel do poder judiciário como garante da democracia e dos direitos fundamentais em detrimento das funções desempenhadas pelos poderes legislativo e executivo, muitas vezes desempenhando o intérprete judicial atribuições que a ele não pertencem.

O protagonismo cada vez maior das Cortes e Tribunais Constitucionais são situações autênticas e recentes propiciadas pelo constitucionalismo contemporâneo. O enfraquecimento do paradigma da legalidade é evidente. A lei que antes era o centro do sistema jurídico e parâmetro de validade das normas, agora é objeto de controle de constitucionalidade. O culto à lei foi substituído pelo culto à jurisprudência constitucional, tonificada por uma nova teoria do Direito baseada na distinção entre regras e princípios, tornando estes na justificação de um decisionismo judicial calcado na subjetividade do intérprete.

Todas essas particularidades que hoje efervescem no campo do direito constitucional, são reflexo de um problema antigo que acompanha o Direito e as discussões que dele se preocupam: a discricionariedade na interpretação jurídica. A aplicação do Direito é dilema que, apesar de antigo, somente recentemente 
SERRAGLIO, Priscila Zilli; ZAMBAM, Neuro José. Hermenêutica e constitucionalismo contemporâneo. Revista Eletrônica Direito e Política, Programa de Pós-Graduação Stricto Sensu em Ciência Jurídica da UNIVALI, Itajaí, v.10, n.2, $1^{0}$ quadrimestre de 2015. Disponível em: www.univali.br/direitoepolitica - ISSN 1980-7791.

tornou-se alvo de sérias e efetivas discussões pelos juristas. Hoje, além de se admitir a importância de uma teoria da interpretação e da argumentação jurídicas, é imprescindível que se pense e se estude uma teoria da decisão, para frear a subjetividade do intérprete no momento do exercício da sua função, bem como para garantir que este se mantenha dentro dos limites a ele permitidos para efetivar suas atribuições.

Para tanto, a hermenêutica tem se mostrado a melhor opção para defender o primado da Constituição e, com ela, o da democracia e das conquistas históricas que afirmam a autonomia do ser humano, porque, da forma como hoje se apresenta, a partir das contribuições de Heidegger e Gadamer, ela nos ensina que $o$ ato de decidir depende de um processo de compreensão simultâneo que ocorre no intérprete, pelo intérprete. A hermenêutica contemporânea também sofreu uma mudança de paradigma, deixando de ser método interpretativo para exprimir um acontecer de sentido, que une a tradição (passado) ao presente, por meio da linguagem.

O giro hermenêutico, então, fez com que a filosofia superasse o paradigma da subjetividade, do sujeito que "assujeita" as coisas, libertando o indivíduo da crença na essência dos objetos, que na modernidade foi referenciada como filosofia da consciência, e permitindo que o sentido interpretado do texto não fosse mera reprodução do pensamento do autor daquelas palavras, mas sim uma reconfiguração do significado do texto atribuída pelo intérprete a partir de sua inserção no mundo, pela sua historicidade, pela sua tradição, pela sua linguagem; isto é, o ato de decidir parte já de uma pré-compreensão de mundo, e essa pré-compreensão parte de um parâmetro, que, no caso dos juízes, intérpretes de ofício, deve ser a Constituição.

A Constituição consagra os valores morais mais caros cultuados pela comunidade política da qual foi originada. Ela representa a tradição, a historicidade de um povo, transformada em enunciados jurídicos a serem vistos como norte do Direito e da atuação política. Nesse sentido, e porque a hermenêutica permite a contextualização do passado histórico no presente plural, ela se apresenta como a melhor forma de se combater a discricionariedade judicial, assegurando que a 
SERRAGLIO, Priscila Zilli; ZAMBAM, Neuro José. Hermenêutica e constitucionalismo contemporâneo. Revista Eletrônica Direito e Política, Programa de Pós-Graduação Stricto Sensu em Ciência Jurídica da UNIVALI, Itajaí, v.10, n.2, $1^{0}$ quadrimestre de 2015. Disponível em: www.univali.br/direitoepolitica - ISSN 1980-7791.

atuação dos juízes permaneça nos limites constitucionais estabelecidos e que a ordem democrática seja cumprida. Tais desafios somente são passíveis de resolução se os juristas comprometerem-se a pensar uma teoria da decisão que busque tais ideais, contribuindo para o Estado Constitucional e Democrático de Direito a partir da crítica externa e interna ao Direito.

O presente artigo, por conseguinte, busca definir o papel da hermenêutica no constitucionalismo contemporâneo, combatendo, para tanto, o seu principal e mais grave desafio, a discricionariedade judicial. Para tanto, utiliza como critério metodológico para o relato dos resultados apresentados, o método dedutivo, assim como as técnicas da pesquisa bibliográfica, da categoria, do conceito operacional, do fichamento, e do referente.

\section{EM DEFESA DA CONSTITUIÇÃO E DO ESTADO DEMOCRÁTICO DE DIREITO - DO PORQUÊ COMBATER O PROTAGONISMO EXACERBADO DA JURISDIÇÃO NO CONSTITUCIONALISMO CONTEMPORÂNEO}

O constitucionalismo passou, ao longo dos anos, por diversas reformas profundas, sempre em busca da limitação do poder, representada historicamente pela tese da separação dos poderes, de Montesquieu, mas sempre sendo influenciado pela história da economia.

O constitucionalismo moderno, iniciado no final do século XVIII, passou por duas fases marcantes, a fase liberal, com o surgimento das primeiras constituições escritas, - a americana (1787), e a francesa (1791) - formais, rígidas, dotadas de supremacia e do controle de constitucionalidade ${ }^{3}$, fase assim caracterizada porque positivou direitos de liberdade e por buscar conter a atuação de um Estado absolutista, vertical e impeditivo do exercício dos direitos do indivíduo; e a fase social, iniciada no século $X X$ para atender às demandas sociais e as desigualdades agravadas com o fim da primeira guerra e com a crise do liberalismo, é marcada pelo Estado Social de Direito, sob as premissas da

\footnotetext{
${ }^{3}$ Veja-se a decisão da Suprema Corte Americana "Marshall Marbury V. Madison", de 1803.
} 
SERRAGLIO, Priscila Zilli; ZAMBAM, Neuro José. Hermenêutica e constitucionalismo contemporâneo. Revista Eletrônica Direito e Política, Programa de Pós-Graduação Stricto Sensu em Ciência Jurídica da UNIVALI, Itajaí, v.10, n.2, $1^{0}$ quadrimestre de 2015. Disponível em: www.univali.br/direitoepolitica - ISSN 1980-7791.

limitação da propriedade privada, da exaltação de direitos trabalhistas e um forte intervencionismo estatal na economia, sendo representado pelas constituições mexicana (1917) e de Weimar (Alemanha, 1919).

O Estado de direito moderno teve como base um forte apego ao texto normativo e, portanto, ao paradigma da legalidade. Contudo, a crença numa razão instrumental e nas promessas da modernidade não deram conta da realidade vivenciada pelas comunidades políticas dos Estados Europeus naquele período histórico, acarretando no fim do constitucionalismo moderno e no advento de um novo modelo de constitucionalismo com o segundo pós-guerra. A partir de então se vive uma nova etapa na história constitucional - o direito mantém suas raízes, mas sofre significativa metamorfose com a jurisprudência de valores, tendência alemã originada a partir do julgamento do "Caso Lüth" e que foi importada para a América Latina, especialmente ao Brasil, pelas Cortes Constitucionais, mas que, ao fim e ao cabo, ao invés de solucionar a problemática da discricionariedade, acabou por intensificá-la ${ }^{4}$.

Atualmente, esse novo período histórico do Estado de Direito tem recebido diversas designações nominativas, sendo as mais usuais "pós-positivismo" e "neoconstitucionalismo". Entretanto, nenhuma delas mostrou-se suficientemente adequada para encontrar consenso entre os juristas que estudam a temática, pois restam incontáveis imprecisões terminológicas e divergências para caracterizar o Estado Constitucional instituído pelos documentos políticos promulgados após-1945. Apesar de não existir uma corrente unitária, apresentam-se uma série de coincidências e tendências comuns que apontam para a formação de uma nova cultura jurídica, na tentativa de explicar as

\footnotetext{
${ }^{4}$ Para fugir do formalismo e da legislação nazista ainda vigente, o tribunal alemão passou a construir argumentos fundados em princípios morais para justificar de forma objetiva suas decisões. Logo, essa jurisprudência de valores passou a ter tanto peso quanto o próprio peso da constituição. Em que pese a crítica de que estaria criando um regime estatal centrado nos valores adotados pelo tribunal alemão, este passou a ser objeto de estudo a nível mundial. A exportação dessa resposta ao resto mundo, em especial para o Brasil, vem trazendo uma série de implicações, como a ampliação da discricionariedade judicial, sob argumento de uma maior racionalidade do discurso jurídico.
} 
SERRAGLIO, Priscila Zilli; ZAMBAM, Neuro José. Hermenêutica e constitucionalismo contemporâneo. Revista Eletrônica Direito e Política, Programa de Pós-Graduação Stricto Sensu em Ciência Jurídica da UNIVALI, Itajaí, v.10, n.2, $1^{0}$ quadrimestre de 2015. Disponível em: www.univali.br/direitoepolitica - ISSN 1980-7791.

transformações do campo do direito no pós-2a guerra. Trindade ${ }^{5}$ aponta três níveis de amplitude semântica da expressão neoconstitucionalismo:

a) explica as especificidades de alguns dos textos constitucionais do pós-2a guerra, onde são incorporadas normas substanciais que condicionam a atuação do Estado na realização de seus fins e objetivos;

b) trata das práticas jurisprudenciais, com parâmetros interpretativos compatíveis com o grau de racionalidade exigido das decisões judiciais;

c) pressupõe a construção de aportes teóricos para compreender os novos textos constitucionais e aperfeiçoar as novas práticas jurisprudenciais.

Por qualquer das vias, o neoconstitucionalismo aponta para a necessidade de uma teoria do direito com ele compatível, vez que o positivismo não foi capaz de explicar as mudanças ocorridas, e demanda a instauração de uma nova prática jurídica que prime pela concretização dos direitos fundamentais, pois o direito contemporâneo passa por uma revolução: como ponto central a jurisdição constitucional ganhou papel de destaque como garantidora dos direitos fundamentais e do regime democrático. Mas não seria essa uma obrigação de todos os poderes?

Juntamente com a ampliação da jurisdição e a diminuição da legislação, houve a ampliação do grau de indeterminação do direito com a emergência dos princípios e a tese alexyana da abertura interpretativa, questão a ser abordada mais à frente. Indiscutivelmente, tais dilemas afetam o paradigma das atuas democracias constitucionais, de modo que suscitam a exigência de se pensar uma teoria da decisão para, em auxílio à teoria da interpretação, controlar as decisões judiciais e o modo como se interpreta e se aplica o Direito.

De fato, considerando esse novo movimento intitulado "neoconstitucionalismo" e os problemas oriundos desse fenômeno, como o papel da jurisdição e o ativismo judicial, muitos autores de renome apontam as contradições jurídicas que este

5 FERRAJOLI, Luigi; STRECK, Lenio; TRINDADE, André Karam (Orgs.). Garantismo, hermenêutica e (neo)constitucionalismo: um debate com Luigi Ferrajoli. Porto Alegre: Livraria do Advogado, 2013, p. 96. 
SERRAGLIO, Priscila Zilli; ZAMBAM, Neuro José. Hermenêutica e constitucionalismo contemporâneo. Revista Eletrônica Direito e Política, Programa de Pós-Graduação Stricto Sensu em Ciência Jurídica da UNIVALI, Itajaí, v.10, n.2, $1^{0}$ quadrimestre de 2015. Disponível em: www.univali.br/direitoepolitica - ISSN 1980-7791.

implica, repensando criticamente o constitucionalismo contemporâneo a partir de outras importantes perspectivas. Assim ocorre com a teoria garantista de Ferrajoli, para quem existiriam duas maneiras de se conceber o fenômeno do constitucionalismo, com ampla influência nas práticas jurídicas: a) o neoconstitucionalismo, sustentado por aqueles que defendem um constitucionalismo principialista ${ }^{6}$, como superação, em sentido jusnaturalista, do positivismo jurídico; e b) o constitucionalismo garantista, pelo qual o constitucionalismo seria a expansão e o completamento do positivismo jurídico. ${ }^{7}$

Ferrajoli rejeita o constitucionalismo principialista, pois, para o jurista italiano, os seus principais aspectos comprometem justamente aquilo que pretendem combater - a tese da conexão entre direito e moral resulta em cognitivismo ético $^{8}$, a diferença qualitativa entre regras e princípios enfraquece a normatividade da constituição ${ }^{9}$ e a ponderação favorece o ativismo judicial $^{10}$, decorrente do problema da discricionariedade na interpretação jurídica. Nesse

${ }^{6}$ Cf. FERRAJOLI (Garantismo, hermenêutica e (neo)constitucionalismo: um debate com Luigi Ferrajoli, p. 18), é caracterizado por três aspectos: i) há relação entre direito e moral, com a incorporaçã̃o, nas Constituições, de princípios de justiça de caráter ético-político; ii) a maioria das normas constitucionais se configura como princípio, sendo estes estruturalmente diversos das regras, representando valores; iii) o primado da argumentação jurídica (ponderação), confiada à atividade dos juízes.

7 Cf. TRINDADE (Garantismo, hermenêutica e (neo)constitucionalismo: um debate com Luigi Ferrajoli, p. 98-99), tal discussão seria uma reedição do debate iniciado por Nicola Mateucci, que, na década de 60 , estudava as relações entre o constitucionalismo e o positivismo, época do apogeu teórico do positivismo (época das traduções para o italiano das obras), e, agora, retomada com o surgimento do neoconstitucionalismo e pela posição de Ferrajoli (conciliar o positivismo com o constitucionalismo e com o garantismo). O caráter crítico do positivismo defendido por Ferrajoli, distinto do paleojuspositivismo ou positivismo clássico, decorre das transformações do constitucionalismo do pós-guerra, que denunciaram o esgotamento do modelo de estado legislativo de direito.

${ }^{8}$ Apesar da defesa de Ferrajoli da separação entre direito e moral, ele admite que a moral é positivada através dos princípios.

9 Veja-se que, para Ferrajoli (Garantismo, hermenêutica e (neo)constitucionalismo: um debate com Luigi Ferrajoli,, p. 40-41), "A diferença entre a maior parte dos princípios e das regras [...] não é estrutural, mas quase que de "estilo". [...] Não existe uma diferença real de estatuto entre a maior parte dos princípios e das regras. A violação sempre faz do princípio uma regra que enuncia proibições e obrigações correspondentes. Assim, a constituição não é definida, na sua parte substancial, unicamente como um conjunto de direitos fundamentais das pessoas, isto é, de princípios, mas como um sistema de limites e vínculos, isto é, de regras destinadas aos titulares dos poderes.".

${ }^{10}$ Registre-se que Ferrajoli não critica a ponderação em si, mas a "excessiva ampliação deste papel na atuação legislativa e na interpretação jurisdicional das normas constitucionais" (2013, p. 47). 
SERRAGLIO, Priscila Zilli; ZAMBAM, Neuro José. Hermenêutica e constitucionalismo contemporâneo. Revista Eletrônica Direito e Política, Programa de Pós-Graduação Stricto Sensu em Ciência Jurídica da UNIVALI, Itajaí, v.10, n.2, $1^{0}$ quadrimestre de 2015. Disponível em: www.univali.br/direitoepolitica - ISSN 1980-7791.

viés, o constitucionalismo garantista seria o novo paradigma do direito e da democracia, justamente porque pode ser definido como

um sistema jurídico e/ou uma teoria do direito que preveem [...] a submissão (inclusive) da legislação a normas relativas à produção não só formais, relativas aos procedimentos (ao quem e ao como), mas também materiais, relativas aos conteúdos das normas produzidas (ao que se deve decidir e ao que não se deve decidir), cuja violação gera antinomias, por comissão, ou lacunas, por omissão. (grifo do autor). ${ }^{11}$

Veja-se, então, que, embora impere um novo paradigma de direito, não há consenso sobre a nomenclatura a designá-lo, motivo pelo qual opta-se, neste artigo, pelo genérico "constitucionalismo contemporâneo" para fazer referência a esse Estado Constitucional de Direito que, entre todas as divergências constituintes do debate neoconstitucional, apresenta como manifestação mais distintiva o protagonismo judicial ${ }^{12}$.

A deificação da jurisprudência constitucional e do judiciário como garantidor dos direitos fundamentais e do regime democrático judicializou a política, permitindo a intervenção dos juízes em questões atinentes aos demais poderes - legislativo e executivo -, colocando em xeque a própria legitimidade dos poderes constituídos e da sua correspondente teoria da separação. Segundo Trindade ${ }^{13}$, isto é consequência da expansão do Poder Judiciário ocorrida após a $2^{a}$ guerra, culminando na "transição do passivismo para o ativismo judicial, sob o argumento de que esse é o único modo através do qual é possível que o direito acompanhe as constantes transformações que marcam as sociedades pósindustriais". Nesses termos, o ativismo judicial consiste na extrapolação dos limites jurisdicionais constitucionalmente estabelecidos para o exercício da sua

${ }^{11}$ FERRAJOLI, Garantismo, hermenêutica e (neo)constitucionalismo: um debate com Luigi Ferrajoli, p. 18.

12 Cf. TRINDADE (Garantismo, hermenêutica e (neo)constitucionalismo: um debate com Luigi Ferrajoli, p. 109), "o termo foi importado da literatura e caracteriza o personagem central herói ou anti-herói - de uma narrativa e de cuja ação dependem todos os acontecimentos subjacentes. Na sua transposição para o campo jurídico, o termo não perde o seu significado de origem, mas é acrescido do sufixo "ismo" para designar uma intoxicação ideológica; por isso, "protagonismo judicial" significa o juiz como o personagem que ocupa posição central no Estado Constitucional de Direito".

13 TRINDADE, Garantismo, hermenêutica e (neo)constitucionalismo: um debate com Luigi Ferrajoli, p. 109. 
SERRAGLIO, Priscila Zilli; ZAMBAM, Neuro José. Hermenêutica e constitucionalismo contemporâneo. Revista Eletrônica Direito e Política, Programa de Pós-Graduação Stricto Sensu em Ciência Jurídica da UNIVALI, Itajaí, v.10, n.2, $1^{0}$ quadrimestre de 2015. Disponível em: www.univali.br/direitoepolitica - ISSN 1980-7791.

função de intérprete e aplicador do direito, arriscando de forma desnecessária as recentes conquistas democráticas.

Guardadas as especificidades da realidade jurídica brasileira, em terrae brasilis, apesar do alerta de inúmeros juristas em forma de crítica ao ativismo judicial, continua-se apostando no fato de que os juízes defenderão os valores da constituição, a partir da técnica da ponderação. Na prática, os princípios tem feito com que os juízes decidam como queiram, conforme sua consciência, de maneira individualista e até egoísta (caracterizando o sujeito solipsista, figura alertada por Streck ${ }^{14}$ ), sem atentar para a linearidade da jurisprudência, que deve manter uma coerência (conforme a tese do romance em cadeia de Dworkin ${ }^{15}$ ), para não se perder a integridade do direito. Conforme Trindade ${ }^{16}$, "A proporcionalidade e a razoabilidade surgem como curingas, servindo de muleta para todo e qualquer argumento jurídico. [...] Efeito disso é uma justiça lotérica, marcada pela imprevisibilidade.".

Mesmo sendo dos tribunais a última palavra, não significa que estes não sejam suscetíveis a erros, por isso, juristas como Streck e Ferrajoli entendem que os princípios desempenham a função de fechamento interpretativo do sistema jurídico, já que auferem maior grau de certeza ao direito ao exigir dos juízes somente a atribuição de sentido normativo compatível com a Constituição aos textos legais, impedindo múltiplas respostas.

Em realidade, o que se observa é que os juízes não estão mais interpretando a Constituição, mas se assenhorando dela, a ponto de banalizarem o direito e, com ele, a própria ordem democrática, preocupando a sua desestruturação. Nesse sentido, considerando a expansão do ativismo, decorrente da aproximação entre a civil law e a common law, é necessário que seja pensada uma teoria da decisão adequada ao nosso sistema, estabelecendo critérios e limites de atuação dos

${ }^{14}$ STRECK, Lenio Luiz. O que é isto - decido conforme minha consciência? 4. ed. Porto Alegre: Livraria do Advogado, 2013.

15 DWORKIN, Ronald. 0 império do direito. 2. ed. São Paulo: Martins Fontes, 2010.

16 TRINDADE, Garantismo, hermenêutica e (neo)constitucionalismo: um debate com Luigi Ferrajoli, p. 118-119. 
SERRAGLIO, Priscila Zilli; ZAMBAM, Neuro José. Hermenêutica e constitucionalismo contemporâneo. Revista Eletrônica Direito e Política, Programa de Pós-Graduação Stricto Sensu em Ciência Jurídica da UNIVALI, Itajaí, v.10, n.2, $1^{0}$ quadrimestre de 2015. Disponível em: www.univali.br/direitoepolitica - ISSN 1980-7791.

tribunais durante o processo de interpretação e aplicação do direito, de forma a evitar juízos arbitrários, que resultem em danos irremediáveis à democracia.

\section{A HERMENÊUTICA COMO POSSIBILIDADE PARA A COERÊNCIA E A INTEGRIDADE DO DIREITO - POR UMA TEORIA DA DECISÃO LIMITADORA DA DISCRICIONARIEDADE INTERPRETATIVA}

Palavras são símbolos e precisam de um agente para ser interpretadas, para darIhes sentido e compreensão. Hoje, em razão da crescente complexidade das coisas, precisamos ainda mais da interpretação para des-velar os artifícios humanos, e o direito é um deles. Direito não é só um instrumento, procedimento, técnica de ordem e coerção. É também retórica, argumentação; lida com as palavras para se expandir e contrair. É por isso que não pode ser considerado um simples conjunto de padrões aplicativos.

Nessa linha, a filosofia, quando analisada sob a ótica do direito, pode nos ajudar a compreender o que é o direito, para que serve, quais seus critérios e como deve ser aplicado. O direito não pode se furtar de acompanhar as evoluções históricas, principalmente aquelas advindas da filosofia. É dizer, o direito não pode ficar imune à influência da moral, ainda mais após o fracasso do positivismo verificado no segundo pós-guerra. A filosofia sempre se comprometeu com a verdade, e, por isso, com a linguagem.

A Hermenêutica é o campo da filosofia que estuda a linguagem e a compreensão de mundo que ela propicia. Hermenêutica é um termo que pode ser entendido como interpretação. A preocupação da hermenêutica foi como dizer, como explicar, como interpretar outros textos. É a linguagem explicada pela linguagem. Por isso, é uma área do conhecimento tão cara ao direito, pois, a partir de uma interdisciplinariedade, é possível conjugar os dois saberes para garantir a autonomia do direito em termos de consistência, coerência e integridade. 
SERRAGLIO, Priscila Zilli; ZAMBAM, Neuro José. Hermenêutica e constitucionalismo contemporâneo. Revista Eletrônica Direito e Política, Programa de Pós-Graduação Stricto Sensu em Ciência Jurídica da UNIVALI, Itajaí, v.10, n.2, $1^{0}$ quadrimestre de 2015. Disponível em: www.univali.br/direitoepolitica - ISSN 1980-7791.

Sob tal ótica, existem diversas manifestações a respeito do formalismo jurídico que constituem o movimento contradogmático do pensamento jurídico atual e que visam afastar o modelo liberal de Direito dos objetivos últimos da construção de um novo saber jurídico adaptado às profundas transformações da sociedade e do Estado contemporâneos. Os enfoques das críticas manifestas ao positivismo pressupõem a inspiração de outras áreas do conhecimento jurídico e não-jurídico para explicar e construir o fenômeno jurídico. Como conseqüência, a razão positivista perde espaço para o comprometimento democrático e emancipatório.

Enfim, ao contrário da hermenêutica jurídica dogmática, a hermenêutica jurídicofilosófica assume um caráter predominantemente crítico, fundindo-se a "Filosofia Hermenêutica" de Heidegger e a "Hermenêutica Filosófica" de Gadamer. Os dois teóricos citados possibilitam desvelar e consolidar uma nova hermenêutica jurídica, uma nova forma de interpretação do direito: já não mais se fala em métodos, mas nas condições de operação do intérprete. A hermenêutica, na visão de Silva Filho"17, "passa a ser vista como um 'modo de ser-no-mundo', como uma característica inerente à própria temporalidade e historicidade do ser humano".

Nos caminhos percorridos pelo direito e pela hermenêutica, as críticas ao dogmatismo jurídico tornaram-se mais fortes quando este se manifestou em favor da instauração de uma teoria pura, de um conhecimento desligado das relações práticas entre o intérprete e a realidade. Embora durante a maior parte de sua história, a hermenêutica tenha sido uma técnica que se exercia no domínio da exegese pública, da filologia clássica e da jurisprudência, seu movimento interpretativo mudou de enfoque no século XIX.

A partir de então, a hermenêutica passou por vários momentos, e se expressou por meio de diferentes teorias, separando-se em duas perspectivas distintas: a hermenêutica metodológica enquanto instrumento de técnica, que se atém apenas ao significado, à estrutura da língua, arte de interpretar - denominada

17 SILVA FILHO, José C. M. da. Ensino do Direito e Hermenêutica Jurídica: entre a abordagem metodológica e a viragem lingüística. In. Estudos Jurídicos. Revista de Ciências Jurídicas da Unisinos. vol. 37. n. 101, 2004., p. 9 
SERRAGLIO, Priscila Zilli; ZAMBAM, Neuro José. Hermenêutica e constitucionalismo contemporâneo. Revista Eletrônica Direito e Política, Programa de Pós-Graduação Stricto Sensu em Ciência Jurídica da UNIVALI, Itajaí, v.10, n.2, $1^{0}$ quadrimestre de 2015. Disponível em: www.univali.br/direitoepolitica - ISSN 1980-7791.

também de hermenêutica epistemológica -; e a hermenêutica filosófica enquanto modo de ser, de pensar e constituir o sentido (historicização da língua), que entrelaça a tensão entre o dito e o não-dito - também hermenêutica ontológica, desenvolvida por Heidegger e Gadamer ${ }^{18}$.

Ao interpretarmos e compreendermos, pretendemos dar motivos e razões da nossa forma de ser e de viver, de saber e sentir nossa própria e singular temporalidade. Do ponto de vista filosófico, o sentido não é algo fixo, mas ontológico-histórico. Desse modo, viver consiste numa metamorfose constante. A nova abordagem hermenêutica contemporânea possibilitou um novo embasamento teórico sobre a interpretação e a compreensão do direito. Assim, criaram-se condições para que se construa uma concepção que não seja exclusivamente dogmática, mas que se preocupe com a reconstrução material de sentido, já que mudam constantemente os valores que os fatos imprimem ao texto.

Hans-Georg Gadamer, dando continuidade à proposta de Heidegger (a compreensão consiste no movimento básico da existência humana, donde compreender é a forma originária de realização do ser-no-mundo), afirma que a hermenêutica não é um método para se chegar à verdade, considerando a compreensão o caráter original da vida humana. Gadamer defende uma hermenêutica existencial (a totalidade da existência humana inserida no mundo), ontológica (donde o sujeito se encontra situado em um mundo simbolizado) e filosófica (prática) ${ }^{19}$.

Gadamer discute as condições e as possibilidades de conhecimento e de interpretação a partir da compreensão enquanto experiência humana e faticidade, que corresponde a um processo que pressupõe estar dentro de um

18 Cf. ROHDEN, Luiz. Hermenêutica: inter e/ou transação? Disponível em: <http://www.iphi.com.br/pdfs/HermeneuticaLRohden_artigo.pdf>. Acesso em: 22 dez. 2014, p. $109 / 132$.

19 Cf. GADAMER, Hans-Georg. Verdade e Método - Traços fundamentais de uma hermenêutica filosófica. Petrópolis: Editora Vozes, 1999. CAMARGO, Margarida M. Lacombe. Hermenêutica e argumentação: uma contribuição ao estudo do direito. Rio de Janeiro: Renovar, 2001, p. 29/30. FERREIRA, Nazaré Conte. Da interpretação à hermenêutica jurídica: uma leitura de Gadamer a Dworkin. Porto Alegre: Safe, 2004, p. 40. 
SERRAGLIO, Priscila Zilli; ZAMBAM, Neuro José. Hermenêutica e constitucionalismo contemporâneo. Revista Eletrônica Direito e Política, Programa de Pós-Graduação Stricto Sensu em Ciência Jurídica da UNIVALI, Itajaí, v.10, n.2, $1^{0}$ quadrimestre de 2015. Disponível em: www.univali.br/direitoepolitica - ISSN 1980-7791.

acontecer tradicional (experimentar a situação). Esta hermenêutica de que fala Gadamer é realizada por um sujeito histórico, que parte de condições espaciais e temporais dadas, contando também com estruturas prévias de pré-compreensão, ou seja, partindo de pressupostos ou pré-juízos ${ }^{20}$.

A interpretação, nesse sentido, permite entender a compreensão como uma autocompreensão de quem interpreta. O sujeito que compreende, então, não parte do nada - como uma tabula rasa -, conta com toda sua historicidade que o caracteriza e o define como tal. Desenvolvendo a fala de Heidegger de que "a linguagem é a casa do ser", Gadamer passa a teorizar sobre a universalidade da linguagem para o fenômeno hermenêutico. Para ele, as palavras não são algo que pertence ao ser humano, mas à situação. De acordo com Silva Filho ${ }^{21}$,

[...] a linguagem sempre nos precede, ela é anterior. Estamos sempre e desde sempre, nela. A centralidade da linguagem reside justamente no fato de que 0 mundo somente será mundo, como mundo, se o nomearmos, é dizer se lhe dermos sentido como mundo. Não há mundo em si. O mundo e as coisas somente serão se forem interpretados. Em uma clara remissão ao conceito de mundo cunhado por Heidegger, Gadamer esclarece que é graças à linguagem que os homens têm mundo. É nela que este é representado, o que significa, em outros termos, uma liberdade que temos diante do mundo circundante de denominar, sob nosso prisma, as coisas que nos vêm dele, de tal modo a criarmos o mundo. Assim, a linguagem não pode ser encarada como um mero meio de comunicação, pois ela é o solo sobre o qual a nossa consciência se estabelece.

O universo e tudo que nele se insere, nesse aspecto, só existem a partir do humano, da sua racionalidade e da sua capacidade de comunicação, sua linguagem, a experiência lingüística que este compõe com os seres e com os objetos. Ou seja, é a partir do homem que surge o universo; a racionalidade nos dá consciência da existência. Quando Gadamer trata da tradição, ele considera

${ }^{20}$ Cf. GADAMER, Verdade e Método - Traços fundamentais de uma hermenêutica filosófica, p. 39/45. LEAL, Rogério Gesta. Hermenêutica e direito: considerações sobre a teoria do direito e os operadores. Santa Cruz do Sul: EDUNISC, 2002, 143/153. LIXA, Ivone Fernandes Morcilo. Hermenêutica \& Direito - uma possibilidade crítica. Curitiba: Juruá. 2005, p. 61/88.

${ }^{21}$ SILVA FILHO, Ensino do Direito e Hermenêutica Jurídica: entre a abordagem metodológica e a viragem lingüística, p. 70 
SERRAGLIO, Priscila Zilli; ZAMBAM, Neuro José. Hermenêutica e constitucionalismo contemporâneo. Revista Eletrônica Direito e Política, Programa de Pós-Graduação Stricto Sensu em Ciência Jurídica da UNIVALI, Itajaí, v.10, n.2, $1^{0}$ quadrimestre de 2015. Disponível em: www.univali.br/direitoepolitica - ISSN 1980-7791.

mais do que somente o que restou do passado, valora o conceito, implicando nele um outro sentido, o sentido de transmissão. Ou seja, se algo é transmitido, é dito ao ser humano no mito, nos costumes, nos textos. Assim, o que está em questão é como o nosso passado nos condiciona.

Para podermos compreender a realidade presente, devemos analisar a construção histórica do pensamento hermenêutico moderno, sendo uma forma de representação da reflexão prática, visando compreender para criar-se possibilidades de agir. O ato compreensivo, como um diálogo, é movido pelo desejo de superação de um ponto de vista - de um horizonte - e de uma verdade construída. Assim, compreender é o modo de ser da presença. Portanto, na visão gadameriana, a interpretação tende a uma compreensão fragmentada da realidade, sendo fundamental olhar o passado com os olhos do presente para então melhorar e evoluir a realidade e suas formas interpretativas, aproximandoas.

Em Gadamer, o termo "pré-juízo/pré-conceito" significa que a primeira atitude que se toma ao compreender algo é elaborar um projeto inicial, prévio, pois nunca se começa no vazio. Gadamer diz que "quem quiser compreender um texto realiza sempre um projetar. Tão logo apareça um primeiro sentido no texto, o intérprete prelineia um sentido do todo"22. Desse modo quando entendemos um texto, o fazemos "sobre a base de expectativas de sentido que extraímos de nossa própria relação precedente com o assunto" ${ }^{23}$. A interpretação é sempre algo produtivo (e não reprodutivo); é uma tarefa criativa. Gadamer mostra que o que o intérprete faz não é buscar o "sentido original" do texto, mas renovar a efetividade histórica do texto, referindo-se à nova situação na qual procede a interpretação.

Os pré-juízos do intérprete podem ser tanto legítimos/positivos/autênticos, como também ilegítimos/negativos/inautênticos. Os primeiros são aqueles que estão de acordo com o objeto de estudo em questão (por exemplo, um texto); os

22 Cf. SILVA FILHO, Ensino do Direito e Hermenêutica Jurídica: entre a abordagem metodológica e a viragem linguística, p. 40/41.

23 Cf. SILVA FILHO, Ensino do Direito e Hermenêutica Jurídica: entre a abordagem metodológica e a viragem linguística, p. 40/41. 
SERRAGLIO, Priscila Zilli; ZAMBAM, Neuro José. Hermenêutica e constitucionalismo contemporâneo. Revista Eletrônica Direito e Política, Programa de Pós-Graduação Stricto Sensu em Ciência Jurídica da UNIVALI, Itajaí, v.10, n.2, $1^{0}$ quadrimestre de 2015. Disponível em: www.univali.br/direitoepolitica - ISSN 1980-7791.

segundos são aqueles que apenas não desacordam do objeto de estudo, mas que também impedem a verdadeira compreensão, produzindo mal-entendidos. Sendo assim, os pré-juízos negativos devem ser suspendidos de validade. É por isto que a compreensão se inicia onde algo nos interpela, pois o mal-entendido suscita nosso questionamento. ${ }^{24} \mathrm{~A}$ verdadeira compreensão, então, efetiva-se a partir da autoconsciência em relação aos nossos próprios preconceitos. O presente, então, está sempre em formação, pois a cada nova situação de compreensão, devemos por à prova nossos pré-conceitos ${ }^{25}$.

Para Gadamer, a compreensão se origina da fusão de horizontes, fruto da dialética compreensiva que contrasta passado e presente. O diálogo é uma atitude de "abertura" ao outro, é a disponibilidade de aceitar sua "verdade", porém não é uma relação de domínio, senão um "mútuo escutar". Sob tal ótica ocorre o diálogo hermenêutico, que funde o horizonte do intérprete com o horizonte do autor do texto e o texto em si, permitindo que se revele uma nova expressão de algo. A fusão de horizontes consiste em se ter consciência da alteridade do outro (caráter ou qualidade do que é outro), ou seja, infere uma abertura ao dizer do outro (aquele que interpelou o intérprete, instigando nele o desejo de compreendê-lo: um texto qualquer, por exemplo).

Gadamer, portanto, não busca o esquecimento das próprias opiniões, mas a abertura à opinião do outro. Segundo ele, ao tratar da distância temporal que separa o intérprete do texto, "o sentido de um texto supera o seu autor não ocasionalmente senão sempre"26. É a distância no tempo que torna possível a tarefa crítica da hermenêutica: distinguir os preconceitos verdadeiros daqueles que produzem mal-entendidos. Compreender melhor um texto não significa expressar de modo mais fiel o pensamento do autor, mas trazer à tona o sentido

24 Cf. GADAMER apud SILVA FILHO, Ensino do Direito e Hermenêutica Jurídica: entre a abordagem metodológica e a viragem linguística, p. 50.

25 Cf. STRECK (O que é isto - decido conforme minha consciência? 4. ed. Porto Alegre: Livraria do Advogado, 2013, p. 110), "[...] não é demais recordar que tanto em Gadamer como em Dworkin é possível distinguir boas e más decisões (pré-juízos autênticos/legítimos e inautênticos/ilegítimos) que, quaisquer que sejam seus pontos de vista sobre a justiça e o direito a um tratamento igualitário, os juízes devem aceitar uma restrição independente e superior, que decorre da integridade nas decisões que proferem.".

26 GADAMER apud CAMARGO, Hermenêutica e argumentação: uma contribuição ao estudo do direito, p. 43. 
SERRAGLIO, Priscila Zilli; ZAMBAM, Neuro José. Hermenêutica e constitucionalismo contemporâneo. Revista Eletrônica Direito e Política, Programa de Pós-Graduação Stricto Sensu em Ciência Jurídica da UNIVALI, Itajaí, v.10, n.2, $1^{0}$ quadrimestre de 2015. Disponível em: www.univali.br/direitoepolitica - ISSN 1980-7791.

novo que o texto adquire no contato com um horizonte histórico posterior em relação àquele no qual foi produzido ${ }^{27}$.

Em consonância com toda a sua obra, Gadamer explora a questão do círculo hermenêutico criada a partir da dinâmica existencial de Heidegger de que sempre nos movemos dentro do que já foi compreendido. Na visão gadameriana, o círculo hermenêutico é entendido como a circularidade que consiste no retorno reflexivo e contínuo aos nossos pré-juízos e pré-conceitos, possuindo a forma de uma espiral, já que seu sentido é inesgotável e é contínuo o aprofundamento e aplicação da compreensão, configurando-se com a aplicação do texto em um contexto existencial ${ }^{28}$.

A aplicação faz-se necessidade em qualquer ramo da hermenêutica, mas esta não pode estar desvinculada da mediação com o presente. Nesse contexto, a aplicação não pode ser desvinculada da hermenêutica jurídica, pois, para Gadamer, a pré-compreensão interpretativa advém da tradição, que está na base de um processo compreensivo de atualização ao momento presente, aplicando-se o compreendido, isto é, exarando a fundamentação da decisão, na realidade atual. Segundo Silva Filho ${ }^{29}$,

Para Gadamer [...], 'a aplicação não quer dizer aplicação ulterior de algo comum dado, compreendida primeiro em si mesma, a um caso concreto, mas é, antes, a verdadeira compreensão do próprio comum que cada texto dado representa para nós. A compreensão é uma forma de efeito, e se sabe a si mesmo como tal efeito'. Em síntese, a tese do autor é de que não se trata primeiro de compreender um texto para depois poder aplicá-lo às situações práticas e cotidianas. A compreensão traz em si o momento da aplicação. Para Gadamer, os três momentos (aplicação, compreensão e interpretação) formam um processo unitário.

27 Cf. SILVA FILHO, Ensino do Direito e Hermenêutica Jurídica: entre a abordagem metodológica e a viragem linguística, p. 54.

28 Cf. FERREIRA, Da interpretação à hermenêutica jurídica: uma leitura de Gadamer a Dworkin, p. 42/43.

${ }^{29}$ SILVA FILHO, Ensino do Direito e Hermenêutica Jurídica: entre a abordagem metodológica e a viragem lingüística, p. 57-64 
SERRAGLIO, Priscila Zilli; ZAMBAM, Neuro José. Hermenêutica e constitucionalismo contemporâneo. Revista Eletrônica Direito e Política, Programa de Pós-Graduação Stricto Sensu em Ciência Jurídica da UNIVALI, Itajaí, v.10, n.2, $1^{0}$ quadrimestre de 2015. Disponível em: www.univali.br/direitoepolitica - ISSN 1980-7791.

Nesse sentido, Gadamer e Heidegger discordam da neutralidade kelseniana, onde se conhece primeiro e depois se interpreta de maneira neutra, eles afirmam que tudo se constrói junto. No Direito, os três momentos correspondem a uma decisão de caráter concreto ${ }^{30}$. "Aplicar significa respeitar a experiência concreta e levar em consideração as circunstâncias particulares em que teve lugar o ato de interpretar" ${ }^{\prime 31}$.

A partir desse contexto, Streck se utiliza da hermenêutica filosófica para construir sua crítica ao problema da discricionariedade, apresentando uma teoria da decisão que permite o fortalecimento da autonomia do Direito pela preservação da democracia e de uma normatividade vigorosa da Constituição, já que a fundamentação das decisões é uma conquista histórica e um direito do cidadão.

É rotineiro perceber nos juízes um posicionamento de que primeiro decidem (chegam a uma conclusão), para depois fundamentar o julgamento. Com efeito, a partir de um olhar hermenêutico, é possível afirmar o contrário, a decisão só existe porque já se encontrou o "fundamento". Ou seja, a fundamentação é fruto de uma pré-compreensão do intérprete a partir da sua historicidade contextualizada no momento presente; é produto do modo-de-ser-no-mundo do intérprete que o levou a assim se posicionar.

Assim, considerando que o Direito não se pode blindar aos demais saberes, devendo com eles interagir, pois também é cultural, não pode ficar imune à mutação paradigmática ocorrida na filosofia aqui representada. É dizer, o Direito, para não submergir na complexidade contemporânea, mas acompanhá-la, deve,

30 Cf. MAIA (O embasamento epistemológico como legitimação do conhecimento e da formação da lei na modernidade: uma leitura a partir de Descartes. Disponível em Mundo Jurídico <http://www.mundojuridico.adv.br/sis_artigos/artigos.asp?codigo=727>. Acesso em: 22 dez. 2014, p. 73-74), o sentido da palavra é construído na experiência e não um dado já existente; o sentido da palavra não é absoluto, mas construído pelo intérprete, em determinadas circunstâncias fáticas e históricas. Daí a conclusão de que toda interpretação jurídica é aplicação, sendo adotado o modelo da filosofia prática concebida por Aristóteles na qual razão e ética se confundem, pois não interessa apenas o saber abstrato, mas o saber concreto, o saber para o outro, sendo superada a separação artificial, operada pela tradição idealista, entre a ciência e a ética. Procura-se prestigiar uma filosofia prática que busque a valorização de uma interpretação prática para o direito, ao invés de uma interpretação puramente teórica e abstrata.

${ }^{31}$ LAMEGO apud SILVA FILHO, Ensino do Direito e Hermenêutica Jurídica: entre a abordagem metodológica e a viragem lingüística, p. 101. 
SERRAGLIO, Priscila Zilli; ZAMBAM, Neuro José. Hermenêutica e constitucionalismo contemporâneo. Revista Eletrônica Direito e Política, Programa de Pós-Graduação Stricto Sensu em Ciência Jurídica da UNIVALI, Itajaí, v.10, n.2, $1^{0}$ quadrimestre de 2015. Disponível em: www.univali.br/direitoepolitica - ISSN 1980-7791.

da mesma forma, sofrer uma transformação crítica, a começar pela sua aplicação, onde se instaura a problemática jurídica mais preocupante no momento, a discricionariedade interpretativa.

O primeiro passo já foi dado, a averiguação do problema. Resta investigar os meios para solucioná-lo. A hermenêutica filosófica, aliada à ciência jurídica, confere aos juristas um novo rumo a trilhar em direção a tal objetivo, desconstruindo o sujeito moderno, intérprete de matriz positivista, baseado na subjetividade, que constrói o seu próprio objeto de conhecimento, desconsiderando a tradição construída pela comunidade política da qual faz parte.

Com Kelsen, o positivismo intensificou a aposta em uma racionalidade teórica sem atentar para o contexto prático de onde as questões jurídicas são provenientes, separando radicalmente direito e moral, fato e direito, texto e norma, validade e legitimidade, e assim por diante e transformando a lei em uma razão autônoma ao descolá-la do mundo concreto. Desse modo, os problemas jurídicos práticos foram desconsiderados pela ciência do direito, donde a aplicação da norma era encarada como um problema de vontade, tendo o intérprete discricionariedade para decidir o sentido do direito no limite do texto normativo.

No entanto, a racionalidade puramente teórica defendida por Kelsen se mostrou impotente para dar conta da realidade propiciada pela última grande guerra. Verificou-se, então, ser necessário a aproximação do direito do mundo prático, situação observada a partir do surgimento da teoria dos princípios e do entrelaçamento entre direito e moral, positivando os valores sociais e a moral na Constituição.

Contudo, e apesar das mudanças filosóficas paradigmáticas, as teorias positivistas recusaram-se a fundar suas epistemologias numa racionalidade que desse conta do agir propriamente dito. E, assim, a aplicação do direito continuou assujeitando-se à discricionariedade interpretativa dos juízes, mas agora com a nova roupagem da teoria alexyana da abertura argumentativa dos princípios. Daí a preocupação de Streck com o sujeito solipsista, que produz a resposta jurídica 
SERRAGLIO, Priscila Zilli; ZAMBAM, Neuro José. Hermenêutica e constitucionalismo contemporâneo. Revista Eletrônica Direito e Política, Programa de Pós-Graduação Stricto Sensu em Ciência Jurídica da UNIVALI, Itajaí, v.10, n.2, $1^{0}$ quadrimestre de 2015. Disponível em: www.univali.br/direitoepolitica - ISSN 1980-7791.

a casos práticos a partir da sua consciência, esquecendo-se de que integra uma comunidade política de onde retira a validade e a legitimidade da sua atuação ${ }^{32}$.

Tal situação é facilmente visualizada pelo fenômeno do ativismo judicial que vem tomando proporções avassaladoramente preocupantes, a ponto de chegar a influenciar a produção legislativa, como se verifica no Anteprojeto de Código Brasileiro de Processos Coletivos. Nos dizeres de Streck:

Com efeito, o Anteprojeto de Código Brasileiro de Processos Coletivos, [...] retrata muito bem essa indevida recepção do "ativismo do Bundesverfassungsgericht", o que se pode ver pelos explícitos dispositivos que objetivam a flexibilização da técnica processual, seguido do consequente aumento dos poderes do juiz, que poderá, produzir (sic) provas de ofício. [...] Ou seja, o Código já nasce com déficit de democracia ao deslocar o problema da concretização dos direitos dos demais Poderes e da Sociedade em direção ao Judiciário. Trata-se, evidentemente, de um grande paradoxo: como é possível que um Código, cuja pretensão maior é o incremento de mecanismos de acesso à justiça, aposte no ativismo judicial como um de seus corolários? ${ }^{33}$

Os ativismos, ao fim e ao cabo, deságuam em decisionismos, ou seja, os juízes decidem fora dos parâmetros da lei e justificam suas decisões em suas convicções pessoais. Outro sintoma, e talvez o mais descabido deles, está na força do princípio do livre convencimento, que autoriza o juiz a formar livremente o seu convencimento com base nas provas submetidas ao contraditório. Ocorre que de nada adianta garantir o direito de prova se a gestão probatória é exclusiva do juiz.

Ativismos, decisionismos, individualismo, subjetividade e discricionariedade são todas facetas de um mesmo mosaico, entendido erroneamente pela doutrina e pelos juízes, que passam a defender a temática, louvando a "decisão heroica" do

32 Cf. STRECK (O que é isto - decido conforme minha consciência?, p. 48), "Aliás, seria incompatível com a democracia que a Constituição autorizasse o juiz a buscar em outros 'espaços', ou fora deles, as fontes para complementar a lei. Seria como permitir que a Constituição autorizasse ser complementada por qualquer aplicador, à revelia do processo legislativo regulamentar (portanto, à revelia do princípio democrático).".

${ }^{33}$ STRECK, 0 que é isto - decido conforme minha consciência?, p. 21-22. 
SERRAGLIO, Priscila Zilli; ZAMBAM, Neuro José. Hermenêutica e constitucionalismo contemporâneo. Revista Eletrônica Direito e Política, Programa de Pós-Graduação Stricto Sensu em Ciência Jurídica da UNIVALI, Itajaí, v.10, n.2, $1^{0}$ quadrimestre de 2015. Disponível em: www.univali.br/direitoepolitica - ISSN 1980-7791.

intérprete que "efetiva direitos contidos em princípios" (criados pelo juiz), face ao ócio e ao convencionalismo legislativos brasileiros.

Lenio destaca que, em razão do solipsismo, a dificuldade tem sido de se fortalecer um espaço democrático de edificação da legalidade, plasmado no texto constitucional. A democracia e os avanços passam a depender das posições individuais dos juízes, pois a justiça emana exclusivamente de sua consciência. "O juiz não se subordina a nada, a não ser ao tribunal de sua razão"34.

Nessa linha, também a doutrina jurídica não contribui para a autonomia do direito, pois permanece presa a essa razão teórica e teima em simplificar o direito, incentivando a busca de novos valores pela jurisprudência, conforme o subjetivismo do intérprete na análise do texto normativo (conforme a consciência e a livre conviç̧ão do juiz). É como se o jurista ignorasse o contexto significativo em que está inserido, partindo de um "grau zero" de sentido; como se o jurista não estivesse inserido em um "modo de ser no mundo", um mundo que ignora os paradigmas do conhecimento.

Parte da dogmática jurídica, o senso comum teórico, reflete, portanto, um saber não crítico-reflexivo, que reproduz enunciados padronizados, conceitos prontos e fora de contexto, como se verifica naqueles professores de cursinhos que fazem apologia a simplificar o direito. Essa massificação do direito também é notada na indústria dos resumos e manuais de direito. Porque a produção doutrinária vive hoje a reproduzir o produzido pelos juízes, Lenio insiste, então, que o papel da doutrina deve ser redefinido. As decisões judiciais, principalmente, aquelas finais, devem ser criticadas, analisadas com rigor argumentativo. Caso contrário, se está incentivando a discricionariedade na interpretação do direito ${ }^{35}$. Isso demonstra que os juristas ainda não conseguiram superar o positivismo jurídico, que tem na discricionariedade a sua maior marca.

Isso nos remete a refletir criticamente sobre a pergunta abordada pelo mesmo autor em seu artigo "Aplicar ou obedecer à letra da lei é uma atitude

\footnotetext{
${ }^{34}$ STRECK, $\mathbf{O}$ que é isto - decido conforme minha consciência?, p. 26.

${ }^{35}$ STRECK, $\mathbf{O}$ que é isto - decido conforme minha consciência?, p. 83.
} 
SERRAGLIO, Priscila Zilli; ZAMBAM, Neuro José. Hermenêutica e constitucionalismo contemporâneo. Revista Eletrônica Direito e Política, Programa de Pós-Graduação Stricto Sensu em Ciência Jurídica da UNIVALI, Itajaí, v.10, n.2, $1^{0}$ quadrimestre de 2015. Disponível em: www.univali.br/direitoepolitica - ISSN 1980-7791.

positivista?"36. Ora, porque vivemos em um Estado democrático de direito, temos o dever de cumprir a lei, aqui entendida como integrante do ordenamento constitucional e em conformidade a ele, pois esse é um dos preços impostos pelo direito e pela democracia. Isso é, portanto, um avanço considerável; é levar o texto jurídico a sério ${ }^{37}$.

No sentido do paradigma hermenêutico hoje vivenciado, o cumprimento da lei não é mais uma aplicação instrumental, mecânica, automática do texto da lei, como era para o positivismo; é mais uma aplicação do direito baseada na Constituição, ela seria o pano de fundo da pré-compreensão do direito, que dá sentido à norma - esclarecendo que a decisão, assim, nunca é uma escolha, não há margem para a discricionariedade.

Obedecer "à risca o texto da lei" democraticamente construído não tem nada a ver com o positivismo exegético. Na exegese, a moral ficava de fora; hoje, no constitucionalismo contemporâneo, ela é cooriginária, positivada através dos princípios constitucionais, base da sociedade civilizada. Ressalte-se, portanto, que, hoje, vive-se sobre o signo de outra legalidade, aquela estabelecida pelo texto constitucional. Assim, como afirma Streck ${ }^{38}$ : "Em suma: o que não podemos fazer é cumprir a lei só quando nos interessa".

Aliás, nesse ponto, importante frisar a confusão relacionada aos princípios gerais do direito, de um lado, e de outro, os princípios constitucionais. Não se pode falar em existência simultânea de princípios constitucionais (cuja aplicação é compulsória) com os princípios gerais do direito, que são instrumentos criados para compor "lacunas" ou obscuridades da produção legislativa, resolvendo dilemas interpretativos do texto legal. Os princípios constitucionais, ao contrário,

\footnotetext{
${ }^{36}$ STRECK, Lenio Luiz. Aplicar a letra da lei é uma atitude positivista?. Novos Estudos Jurídicos, Itajaí, v. 15, n. 1, p. 158-173, jan./abr. 2010.

37 Streck (O que é isto - decido conforme minha consciência?, p. 105), assevera que deve haver a compreensão do nível teórico sob o qual estão assentadas as projeções teóricas efetuadas (não pode ocorrer uma mixagem de teorias) - pois o problema da atribuição de sentido discricionária permite a conveniência de um eterno retorno, por vezes, do objetivismo do juiz boca da lei, e por outras, do subjetivismo da filosofia da consciência.
}

${ }^{38}$ STRECK, Aplicar a letra da lei é uma atitude positivista?, p. 171. 
SERRAGLIO, Priscila Zilli; ZAMBAM, Neuro José. Hermenêutica e constitucionalismo contemporâneo. Revista Eletrônica Direito e Política, Programa de Pós-Graduação Stricto Sensu em Ciência Jurídica da UNIVALI, Itajaí, v.10, n.2, $1^{0}$ quadrimestre de 2015. Disponível em: www.univali.br/direitoepolitica - ISSN 1980-7791.

porque representam a introdução da moral no direito, reforçam os ideais de integridade e coerência, servindo para fechar o sistema jurídico.

É aí que se verifica a influência da teoria de Dworkin na construção da teoria da decisão jurídica de Lênio, porque ele também aposta nos princípios como forma de integração e linearidade do direito, limitando a interpretação do texto normativo, e impedindo a discricionariedade judicial. Isso impediria que juízes se tornassem legisladores, criando direito, e garantiria o direito fundamental de todo o cidadão à obtenção das respostas (julgamentos) em conformidade com a Constituição (direito à devida fundamentação) ${ }^{39}$.

Frise-se que a teoria da distinção entre princípios e regras foi formulada por Dworkin, mas sofreu alterações ao ser considerada por Alexy na sua "teoria dos direitos fundamentais" ${ }^{\prime 40}$, na qual ele afirma que as regras sofrem subsunção, e os princípios sofrem ponderação, estes dando um sentido de abertura interpretativa ao direito. Aqui, também, fica evidente a discricionariedade existente na ponderação dos princípios. A tese de Alexy é utilizada de maneira equivocada pelos juristas brasileiros, pois a sua aplicação decorre de uma escolha direta entre o princípio que mais pesa no balanceamento feito sob o caso concreto, e isso abre espaço para as mais diversas respostas para casos idênticos. Ou seja, permite a discricionariedade abertamente.

$\mathrm{Na}$ prática, a proporcionalidade, que deveria ser aplicada como princípio, é aplicada como se fosse uma regra, sendo utilizada exatamente da mesma forma

39 Cf. STRECK (O que é isto - decido conforme minha consciência?, p. 110), "Na especificidade, Dworkin, ao combinar princípios jurídicos com objetivos políticos, coloca à disposição dos juristas/intérpretes um manancial de possibilidades para a construção/elaboração de respostas coerentes com o direito positivo - o que confere uma blindagem contra discricionariedades (pode-se chamar a isso de "segurança jurídica") - e com a grande preocupação contemporânea do direito: a pretensão de legitimidade.".

40 A forma de garantia da racionalidade da decisão se daria por conta da análise dos princípios da adequação e da necessidade, situados no campo fático. Antes de se refletir sobre a resolução de um conflito de princípios, haveria uma análise fática prévia, de forma a aferir se o conflito estaria realmente instaurado, de forma a evitar a vagueza de uma decisão a respeito de conflito de princípios não amparada por um caso concreto. Nessa condição, "O melhor direito, ou o direito válido, é aquele que atinge de forma mais veemente a estrutura do balanceamento, cuja valoração para o alcance dessa estrutura acontece subjetivamente por conta de um cálculo racional desenvolvido pelo intérprete." (NETO, In: FERRAJOLI, Luigi; et al. Garantismo, hermenêutica e (neo)constitucionalismo: um debate com Luigi Ferrajoli. Porto Alegre: Livraria do Advogado, 2013, p. 159, grifei). 
SERRAGLIO, Priscila Zilli; ZAMBAM, Neuro José. Hermenêutica e constitucionalismo contemporâneo. Revista Eletrônica Direito e Política, Programa de Pós-Graduação Stricto Sensu em Ciência Jurídica da UNIVALI, Itajaí, v.10, n.2, $1^{0}$ quadrimestre de 2015. Disponível em: www.univali.br/direitoepolitica - ISSN 1980-7791.

que aquilo que se pretende combater; isso porque, ao contrário da afirmação de que a abertura semântica do direito provém dos princípios, é a regra que abre a interpretação, pois pretende-se universalizante/generalizante, a abarcar todos os casos, e tudo que se absolutiza, se esvazia. A regra trata de diversas possibilidades e de nenhuma situação concreta. É nesse sentido que o princípio individualiza a aplicação do direito, pois ele "cotidianiza" a regra. É por isso que o direito não cabe na regra, deve ser construído pelos princípios.

De todo modo, tal distinção (entre princípios e regras), apesar de não ser totalmente descabida, não mais se sustenta de maneira rígida no atual Estado Constitucional de Direito, vez que as regras também são suscetíveis de ponderações, assim como os princípios, que seguidamente também se comportam como regras ${ }^{41}$. Assim, se o que se pretende é a preservação da independência da jurisdição, da separação dos poderes e da democracia (e da consequente legitimidade política), a utilização da ponderação como álibi para a criação jurisdicional de princípios morais que nem sequer existem pela Constituição deve ser combatida ferrenhamente, esse é o papel da doutrina e de todos os juristas empenhados em pensar o direito: o comprometimento com a integridade a autonomia do direito através de constrangimentos epistemológicos pela crítica constante à atuação dos poderes.

\section{CONSIDERAÇÕES FINAIS}

Com as mudanças ocorridas no campo jurídico após o ano de 1945, a teoria geral do direito deu um giro de 180 graus. Antes, a validade dos direitos fundamentais era reconhecida à medida que estes estavam contidos na lei; hoje, o enunciado normativo da legislação somente tem validade se respeita o conteúdo essencial dos direitos fundamentais constitucionalizados.

41 Cf. FERRAJOLI (Garantismo, hermenêutica e (neo)constitucionalismo: um debate com Luigi Ferrajoli,, p. 38), "[...] mesmo as regras, inclusive as penais, às quais se exige a máxima taxatividade, quando são observadas exsurgem como princípios, que não se aplicam, mas se respeitam [...]. É possível afirmar, inclusive, que por trás de cada regra existe um princípio [...]. Inversamente, também os princípios reguladores, quando são violados, aparecem como regras, que não se respeitam, mas se aplicam [...].". 
SERRAGLIO, Priscila Zilli; ZAMBAM, Neuro José. Hermenêutica e constitucionalismo contemporâneo. Revista Eletrônica Direito e Política, Programa de Pós-Graduação Stricto Sensu em Ciência Jurídica da UNIVALI, Itajaí, v.10, n.2, $1^{0}$ quadrimestre de 2015. Disponível em: www.univali.br/direitoepolitica - ISSN 1980-7791.

O constitucionalismo moderno, na época do seu início, passou pelas etapas de positivação (fase liberal) e de generalização (fase social) - no sentido de transformar direitos individuais em textos normativos e, em seguida, além de fazer o mesmo com direitos sociais, dando ênfase ao sufrágio universal. Com o advento do Estado Constitucional de Direito, passou-se a primar pela eficácia e pela efetividade desses direitos, que, ante a abrangência dos seus enunciados, demanda uma fundamentação mais consistente do Poder Judiciário quando da sua interpretação e aplicação.

Nesse aspecto, com a relevância adquirida à jurisprudência das Cortes Constitucionais, verifica-se uma atuação mais ativa dos intérpretes jurídicos, ainda mais quando a doutrina, em consonância com a posição defendida nos Tribunais, passa a defender a dicotomia entre princípios e regras, o uso recorrente da ponderação, e, em via reflexa, o "princípio do livre convencimento do juiz" (sic), incentivando que este decida conforme a sua consciência situação que acarreta consequências nefastas para a autonomia do direito e à democracia.

Frise-se, contudo, ser - muito mais que direito - dever do Poder Judiciário, se e quando provocado, ou mesmo ante a inércia de um dos poderes frente à Norma Maior, executar a Constituição para fazer cumprir todo o complexo sistema de direitos que estruturam o ordenamento jurídico, ainda mais quando amparado nos remédios constitucionalmente constituídos para enfrentar o abuso de poder. A decisão judicial, mantida dentro dos parâmetros constitucionais e sem retroceder no quesito de direitos humanos, não afronta a legitimidade do Estado Constitucional Democrático.

Todavia, o neoconstitucionalismo, na versão concebida em terrae brasilis, aposta na mescla entre a jurisprudência dos valores alexyana e o ativismo judicial norte-americano, desaguando na tão combatida discricionariedade, que, involuntariamente, se apoia nos princípios como justificativas para decisionismos. É, por isso, que tal movimento é tão criticado hoje por juristas como Ferrajoli, Streck, Trindade, dentre outros renomados doutrinadores. 
SERRAGLIO, Priscila Zilli; ZAMBAM, Neuro José. Hermenêutica e constitucionalismo contemporâneo. Revista Eletrônica Direito e Política, Programa de Pós-Graduação Stricto Sensu em Ciência Jurídica da UNIVALI, Itajaí, v.10, n.2, $1^{0}$ quadrimestre de 2015. Disponível em: www.univali.br/direitoepolitica - ISSN 1980-7791.

Para que, então, o constitucionalismo contemporâneo consiga alcançar a eficácia e a efetividade pretendidas aos direitos fundamentais constitucionalmente assegurados, ao mesmo tempo em que a discricionariedade precisa ser limitada, também o solipsismo epistemológico e a tese da abertura semântica dos princípios também são sintomas que precisam ser tratados. Nesse contexto, a hermenêutica se apresenta como uma ferramenta adequada para auxiliar o Direito nessa transição paradigmática de superação da modernidade e da sua razão teórico-instrumental.

Toda aplicação do direito, isto é, toda decisão judicial, deve ser construída a partir de um sentido pré-compreendido, com uma fundamentação comprometida com a compreensão daquilo que a comunidade política constrói como direito, pois, como nos ensina a hermenêutica, nenhuma interpretação parte de um grau zero de sentido. Da mesma forma, as decisões judiciais não podem se fundar na subjetividade do intérprete, mas sim na historicidade da coletividade a qual integra, pois o direito é construído na e da tradição, e reeditado na contemporaneidade, através dos princípios, que permitem a introdução do mundo prático dos fatos (casos concretos) nos enunciados da lei, tornando a decisão coerente e adequada à Constituição.

É tarefa contínua, pois, da doutrina, a censura das decisões discricionárias, promovendo "constrangimentos epistemológicos", pois a fundamentação é um direito fundamental. Uma decisão mal fundamentada, portanto é inconstitucional e, portanto, nula (aqui incluídas as sentenças contraditórias, obscuras ou omissas). Por fim, uma ressalva: apesar da crítica contida no presente estudo voltar-se, principalmente, à postura judiciária, pois é ela que vem ganhando ênfase no cenário brasileiro, não significa que um legislativo irresponsável (que aprove leis de conveniência) não mereça a devida censura da jurisdição constitucional, pois nenhum poder está imune à sindicabilidade no Estado Democrático de Direito. 
SERRAGLIO, Priscila Zilli; ZAMBAM, Neuro José. Hermenêutica e constitucionalismo contemporâneo. Revista Eletrônica Direito e Política, Programa de Pós-Graduação Stricto Sensu em Ciência Jurídica da UNIVALI, Itajaí, v.10, n.2, $1^{0}$ quadrimestre de 2015. Disponível em: www.univali.br/direitoepolitica - ISSN 1980-7791.

\section{REFERÊNCIAS DAS FONTES CITADAS}

ALEXY, Robert. Conceito e validade do direito. São Paulo: Martins Fontes, 2009.

CAMARGO, Margarida M. Lacombe. Hermenêutica e argumentação: uma contribuição ao estudo do direito. Rio de Janeiro: Renovar, 2001.

CAZZARO, Kleber; GRADOS, Guido Cesar Aguila; STAFFEN, Márcio Ricardo. Constitucionalismo em mutação. Reflexões sobre as influências do neoconstitucionalismo e da globalização jurídica. Blumenau: Nova Letra, 2013.

DWORKIN, Ronald. Levando os direitos a sério. São Paulo: Martins Fontes, 2002.

O império do direito. 2. ed. São Paulo: Martins Fontes, 2010.

FERRAJOLI, Luigi; STRECK, Lenio; TRINDADE, André Karam (Orgs.). Garantismo, hermenêutica e (neo)constitucionalismo: um debate com Luigi Ferrajoli. Porto Alegre: Livraria do Advogado, 2013.

FERREIRA, Nazaré Conte. Da interpretação à hermenêutica jurídica: uma leitura de Gadamer a Dworkin. Porto Alegre: Safe, 2004.

GADAMER, Hans-Georg. Verdade e Método - Traços fundamentais de uma hermenêutica filosófica. Petrópolis: Editora Vozes, 1999.

KELSEN, Hans. Teoria pura do direito. Coimbra: Armenio Amado, 1979.

LEAL, Rogério Gesta. Hermenêutica e direito: considerações sobre a teoria do direito e os operadores. Santa Cruz do Sul: EDUNISC, 2002.

LIXA, Ivone Fernandes Morcilo. Hermenêutica \& Direito - uma possibilidade crítica. Curitiba: Juruá. 2005.

MAIA, Alexandre da. O embasamento epistemológico como legitimação do conhecimento e da formação da lei na modernidade: uma leitura a partir de Descartes. Disponível em Mundo Jurídico <http://www.mundojuridico.adv.br/sis_artigos/artigos.asp?codigo $=727>$. Acesso em: 22 dez. 2014.

ROHDEN, Luiz. Hermenêutica: inter e/ou transação? Disponível em: <http://www.iphi.com.br/pdfs/HermeneuticaLRohden_artigo.pdf>. Acesso em: 22 dez. 2014.

SILVA FILHO, José C. M. da. Ensino do Direito e Hermenêutica Jurídica: entre a abordagem metodológica e a viragem lingüística. In. Estudos Jurídicos. Revista de Ciências Jurídicas da Unisinos. vol. 37. n. 101, 2004.

STRECK, Lenio Luiz. Aplicar a letra da lei é uma atitude positivista?. Novos Estudos Jurídicos, Itajaí, v. 15, n. 1, p. 158-173, jan./abr. 2010. 
SERRAGLIO, Priscila Zilli; ZAMBAM, Neuro José. Hermenêutica e constitucionalismo contemporâneo. Revista Eletrônica Direito e Política, Programa de Pós-Graduação Stricto Sensu em Ciência Jurídica da UNIVALI, Itajaí, v.10, n.2, $1^{0}$ quadrimestre de 2015. Disponível em: www.univali.br/direitoepolitica - ISSN 1980-7791.

O que é isto - decido conforme minha consciência? 4. ed. Porto Alegre: Livraria do Advogado, 2013.

Verdade e consenso. 5. ed. São Paulo: Saraiva, 2014.

Submetido em: Fevereiro/2015

Aprovado em: Março/2015 